\title{
ESTRATEGIAS DE PREVENCIÓN PARA DISMINUIR LA TRANSMISIÓN VERTICAL DEL VIRUS DE INMUNODEFICIENCIA HUMANA DURANTE LA GESTACIÓN
}

\section{PREVENTION STRATEGIES TO REDUCE VERTICAL TRANSMISSION OF HUMAN IMMUNODEFICIENCY VIRUS DURING GESTATION}

\author{
Katherin Faviola Moreno Reyes ${ }^{1, a}$, Félix Dasio Ayala Peralta ${ }^{1,2, b}$, Carlos Velásquez Vásquez ${ }^{1, c}$
}

\begin{abstract}
RESUMEN
El embarazo en una mujer que vive con el VIH continúa siendo un problema importante de salud que involucra no solo a la gestante si no al producto de la gestación por el alto riesgo de transmitir del virus durante el embarazo, el momento del parto y la lactancia materna.

A pesar de los años transcurridos, los estudios seleccionados siguen reportando que la reducción de la transmisión vertical del VIH se logra con el diagnóstico temprano de la infección en la gestante, disminuyendo la carga viral materna mediante el uso de terapia antirretroviral en el embarazo y en el momento del parto, el nacimiento por cesárea electiva, la supresión de la lactancia materna y la profilaxis antirretroviral en el recién nacido.
\end{abstract}

Palabras clave: Estrategia preventiva; Transmisión vertical; Virus de inmunodeficiencia humana; Gestación.

(Fuente: DeCS BIREME).

\begin{abstract}
Pregnancy in a woman living with HIV continues to be an important health problem that involves not only the pregnant woman but also the product of pregnancy due to the high risk of transmitting the virus during pregnancy, the time of delivery and breastfeeding maternal.

Despite the years the selected studies continue to report that the reduction of vertical transmission of HIV is achieved with the early diagnosis of the infection in the pregnant woman, reducing the maternal viral load using antiretroviral therapy in pregnancy and in timing of delivery, elective cesarean delivery, discontinuation of breastfeeding, and antiretroviral prophylaxis in the newborn.
\end{abstract}

Keywords: Preventive strategy; Vertical transmission; Human immunodeficiency virus; Gestation. (Source: MeSH NLM).

\section{INTRODUCCION}

En la actualidad el embarazo en una mujer que vive con el VIH continúa siendo un problema de salud importante por el alto riesgo que existe de transmisión vertical del virus de la madre a su bebe durante el embarazo, parto y lactancia.

La trasmisión vertical, también denominada trasmisión perinatal o materno infantil del $\mathrm{VIH}$, es el proceso infeccioso que implica el paso del VIH de una gestante infectada hacia su hijo durante el embarazo, trabajo de parto o durante la lactancia ${ }^{1-4}$.
La transmisión vertical se puede producir durante el embarazo en $25-40 \%$ de casos, durante el trabajo de parto en $60-75 \%$ de casos y por lactancia materna en $16 \%$ de casos ${ }^{4,5}$.

Las estrategias de prevención de la transmisión vertical del VIH involucran intervenciones que se realizan en tres momentos importantes del embarazo: el control prenatal, el parto, y la lactancia materna. La intervención de mayor importancia es, sin lugar a duda, el uso de la terapia antirretroviral en forma precoz en lo posible desde el primer trimestre de la gestación; ya que la eficacia de la prevención de la

Instituto Nacional Materno Perinatal. Lima-Perú.

2 Universidad Nacional Mayor de San Marcos. Lima-Perú.

a Licenciada en Obstetricia. Asistente de Unidad de Referencias y Contrarreferencias.

b Médico GínecoObstetra. Profesor Ordinario del Departamento de Ginecología y Obstetricia.

c Médico Pediatra. Asistente del Departamento de Neonatología. Experto en ITS-VIH/SIDA

D Código ORCID: https://orcid.org/0000-0003-2765-8809: Katherin Faviola Moreno Reyes

Citar como: Moreno Reyes KF, Ayala Peralta FD, Velásquez-Vásquez C. Estrategias de prevención para disminuir la transmisión vertical del virus de inmunodeficiencia humana durante la gestación. Rev Peru Investig Matern Perinat. 2021;10(3): 47-53

DOI https://doi.org/10.33421/inmp.20212243

Recibido: 20-07-2021 Aceptado: 30-09-2021 
transmisión perinatal del VIH dependerá tanto de la disminución de carga viral, como el inicio precoz y la duración de terapia antirretroviral durante la gestación ${ }^{2}$. Asimismo, según recomendaciones del Colegio Americano de Obstetricia y Ginecología $[A C O G]^{6}$ el riesgo de transmisión de madre a hijo en gestantes infectadas por el VIH con cargas virales elevadas pueden reducirse realizando cesárea electiva antes del inicio de trabajo de parto y antes de la rotura de membranas, de preferencia cesárea programada a las 38 semanas de gestación, conjuntamente con el uso de terapia antirretroviral materna en el periparto.

La base de la terapia antirretroviral es conseguir que la gestante alcance la supresión de carga viral (menos de mil copias por mililitro) o que ésta sea indetectable (menos de 50 copias por $\mathrm{ml})^{3,7}$.

En el Perú, el uso de antirretrovirales (TAR) en gestantes se inició en 1996 como parte de la política nacional de lucha contra el SIDA; como tratamiento profiláctico en la gestante se usó zidovudina oral desde las 14 semanas, además de la cesárea programada y la suspensión de la lactancia materna; dicho protocolo ha tenido variaciones basadas en la evidencia y recomendaciones internacionales, y en la actualidad el Ministerio de salud de Perú ${ }^{4}$ actualizó la Norma Técnica N¹59-2019/MINSA/ DGIESP "Norma técnica de salud para la prevención de la transmisión materno infantil del VIH, sífilis y hepatitis B" que establece las pautas para el tamizaje, diagnóstico precoz y tratamiento para la prevención de transmisión materno infantil del $\mathrm{VIH}$; donde están incluidos el formato de consentimiento informado para la prueba de despistaje del VIH en la gestante, hoja de consentimiento informado para el inicio de tratamiento antirretroviral en gestante con $\mathrm{VIH}$, y escenarios de manejo con antirretrovirales (TAR) para prevenir la transmisión materno infantil del VIH.

El escenario 1 gestante que por primera vez se le diagnostica la infección por $\mathrm{VIH}$ durante la atención prenatal o con diagnóstico previo que no recibe TAR. El escenario 2 gestante $\mathrm{VIH}$ que estuvo recibiendo TAR antes de su embarazo. El escenario 3 gestante $\mathrm{VIH}$ diagnosticada por primera vez durante el trabajo de parto. Asimismo, para la prevención de transmisión materno infantil dispuso el uso de antirretrovirales combinados en la gestante infectada y el recién nacido expuesto, la culminación del embarazo mediante cesárea electiva, y suspensión de lactancia materna en el recién nacido de madre seropositiva ${ }^{4}$.

Según reportes de Velásquez $\mathrm{C}^{8}$ en el Instituto Nacional Materno Perinatal desde 1996 hasta año
2009, se aplicaron tres guías terapéuticas para la prevención de la transmisión vertical del VIH. Estas guías se diferenciaron en los siguientes esquemas: uno que incluía zidovudina como única droga durante la gestación (primer periodo 1996 a 2001); otro con zidovudina y TARGA (segundo periodo 2006 a 2007), dependiendo si tenían o no criterios para el inicio la terapia de gran actividad; y finalmente al TARGA como único esquema de tratamiento durante el embarazo (tercer periodo 2008 a 2009), protocolo que se usa actualmente aunque con diferente tipo de antirretrovirales. El autor concluyó que los cambios realizados en las guías nacionales habían producido un impacto favorable en la disminución de nacimientos de niños infectados por el VIH en el Instituto Nacional Materno Perinatal reduciendo la transmisión vertical de $6.9 \%$ a $0 \%$.

El objetivo de la investigación es realizar una revisión bibliográfica de diversas publicaciones relacionadas a medidas de prevención para disminuir la transmisión vertical del VIH durante la gestación.

\section{METODOLOGÍA UTILIZADA}

Tipo de estudio. Investigación tipo revisión de publicaciones de carácter descriptivo.

Población y muestra: Estuvo conformada por 340 artículos originales encontrados en la base de datos electrónicos PubMed, Excerpta Medica Base de datos (EMBASE) y Google Scholar a partir del año 2011 al 2020. La muestra fue constituida por 25 estudios observacionales que cumplieron criterios de inclusión de contar con factores asociados de transmisión vertical durante la gestación.

Técnicas e instrumentos. Se realizó el recojo de la información a partir de la de base de datos electrónicos, para ello se elaboró una ficha de recolección de datos ad hoc, para recoger los datos contemplados en el presente estudio.

Procedimientos. Se usó el formato digital en una base datos en Microsoft Excel versión 2010.

Análisis de datos. Se realizó un análisis descriptivo de los datos resumiendo las variables categóricas de los hallazgos expresados como razón de probabilidad $(\mathrm{OR})$ o riesgos relativos (RR) de cada estudio con sus intervalos de confianza al $95 \%$.

Aspectos éticos. Como los datos recopilados de los estudios científicos ya se encuentran publicadas y validadas, la originalidad y autoría de investigaciones fueron respetadas y debidamente consignadas en las referencias bibliográficas. 


\section{HALLAZGOS}

a) Manejo de trabajo de parto y parto de las gestantes infectadas con VIH

El riesgo de transmisión de madre a hijo en gestantes infectadas por el VIH con cargas virales elevadas puede reducirse realizando cesárea antes del inicio de trabajo de parto y antes de la rotura de membranas, mediante cesárea programada, en conjunto con el uso de terapia antirretroviral materna periparto ${ }^{6}$.

Las mujeres deben recibir terapia antirretroviral durante embarazo de acuerdo con las pautas

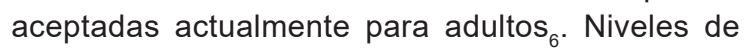
ARN del VIH en plasma en mujeres embarazadas debe ser monitoreado en la primera visita prenatal; 2-4 semanas después de iniciar (o cambiar) los regímenes de terapia antirretroviral combinada (TARc); mensualmente hasta que los niveles de ARN sean indetectables; y luego en al menos cada 3 meses durante el embarazo. Los niveles de ARN del virus de Inmunodeficiencia humana también deben evaluarse aproximadamente a las 34 0/7 a 36 0/7 semanas de gestación para informar decisiones sobre el modo de parto y el óptimo tratamiento del recién nacido. Mujeres embarazadas infectadas con VIH cuyas cargas virales son más de 1000 copias / $\mathrm{mL}$ en o cerca del parto, independientemente de terapia antirretroviral antes del parto, o cuyos niveles se desconocen, deben ser asesorado sobre el beneficio potencial y ofrecer cesárea electiva antes del parto a las 38 0/7 semanas de gestación para reducir el riesgo de transmisión madre a hijo. En esta situación, programar un parto por cesárea como parto pretérmino médicamente indicado a las 38 0/7 semanas de gestación tiene como objetivo disminuir la probabilidad de inicio del trabajo de parto o ruptura de membranas antes del parto. Estos pacientes también deben recibir zidovudina (ZDV) vía intravenosa, idealmente 3 horas antes de la operación como 1 hora dosis de carga intravenosa (2 mg / kg), seguida de continua infusión durante 2 horas ( $1 \mathrm{mg} / \mathrm{kg} / \mathrm{h}$ ) hasta el parto a lograr niveles séricos adecuados del medicamento en la madre y el feto. Esta recomendación se basa en demostración de proporciones significativamente más altas de niveles de ZDV de cordón sangre a madre en mujeres que recibieron ZDV por vía intravenosa durante 3 a 6 horas en comparación con menos más de 3 horas antes del parto. Si el paciente ha optado para el parto vaginal a pesar de la carga viral no suprimida, entonces se debe iniciar ZDV intravenoso al inicio de parto y continuar durante el trabajo de parto hasta el parto junto con otros medicamentos en su actual régimen antirretroviral ${ }^{6}$.
Aunque no se requiere ZDV intravenoso para mujeres con VIH que reciben TARc con ARN del $\mathrm{VIH} 1,000$ copias/ml o menos al final del embarazo, o cerca de parto, o ambos, sin preocupaciones sobre el cumplimiento de o tolerancia a sus regímenes TARc, algunos expertos han expresado su preocupación por la falta de datos adecuados para determinar si la administración intraparto de ZDV intravenoso para estas mujeres proporciona cualquier protección contra la transmisión perinatal. Estos expertos han recomendado la administración de ZDV intravenoso intraparto a mujeres con niveles de ARN en este rango, ya que el riesgo de transmisión es ligeramente mayor (aproximadamente 1-2\%) cuando el ARN del VIH está en el rango de 50 a 999 copias $/ \mathrm{ml}$ en comparación con menos de 50 copias $/ \mathrm{ml}$ (1\% o menos).

Sin embargo, independientemente de la carga viral, en estas circunstancias el médico puede optar por utilizar o no utilizar ZDV intravenoso intraparto basado en juicio clínico. Independientemente de los resultados de la carga viral materna antes del parto, se debe planificar el cuidado y manejo de todos los recién nacidos de mujeres infectadas por el VIH con proveedores de atención pediátrica con experiencia en iniciar y controlar la continuación de la profilaxis terapia antirretroviral para recién nacidos y lactantes en riesgo. Idealmente, este proceso debería ocurrir antes del parto, pero de lo contrario, tan pronto como sea posible después del nacimiento ${ }^{6}$.

b) Estrategias de prevención para disminuir la transmisión vertical del VIH

Con el fin de prevenir la transmisión materno infantil del VIH, la actual norma técnica del Ministerio de Salud del Perú ${ }^{4}$ recientemente aprobada, en base a las recomendaciones internacionales dispone el uso de antirretrovirales combinados (TARc) en la gestante infectada y el recién nacido expuesto, la culminación del embarazo mediante cesárea electiva, así como la alimentación al recién nacido con leche artificial, que aplicados oportunamente, reducen la transmisión materno infantil a menos del $2 \%$, siendo primordial para ello el acceso temprano al control prenatal, tamizaje para VIH y diagnóstico precoz del VIH en la gestante.

Tal como se aprecia en la tabla 1, existen diversas estrategias que contribuyen a la disminución de la transmisión vertical o transmisión materno-infantil (TMI) según estudios seleccionados. Según Huang $\mathrm{KY}$ et $\mathrm{al}^{9}$ con la estrategia de cumplimiento de TARc antes del parto + zidovudina intravenosa intraparto + cesárea electiva + carga viral $<40$ 
copias $/ \mathrm{ml}$ + supresión de lactancia, la tasa de transmisión alcanza al $0 \%$. Según PosadasRobledo $\mathrm{FJ}^{3}$ con estrategia de cesárea electiva con TARc el $R R=0.7$. Por otro lado, con baja carga viral y TARc, reportes de Briand $\mathrm{N}$ et $\mathrm{al}^{10}$, encuentra $0.3 \%$ de TMI. Asimismo, Scott R et $\mathrm{al}^{11}$ en Latinoamérica y El Caribe (Argentina, Bahamas, Brasil, México, Perú y Jamaica) reporta cifras de tasa de transmisión vertical a las 40 semanas o más de edad gestacional de 0,5\%; y menos de 40 semanas $0,3 \%$. En el Perú, Velásquez $\mathrm{C}^{8}$, reporta los cambios realizados en las guías nacionales han producido un impacto favorable en la disminución de nacimientos de niños infectados por el VIH en el Instituto Nacional Materno Perinatal, en gestantes que cumplieron con terapia antirretroviral la TMI de $6.9 \%$ disminuyó a $0 \%$.

Tabla 1. Estrategias de prevención para disminuir la transmisión vertical del VIH, según estudios seleccionados.

\begin{tabular}{|c|c|c|c|c|}
\hline Autor/año/País & Muestra & $\begin{array}{l}\text { Estrategias } \\
\text { preventivas }\end{array}$ & $\begin{array}{c}\text { Resultados de } \\
\text { transmisión vertical } \\
\text { del VIH }\end{array}$ & Conclusión \\
\hline $\begin{array}{l}\text { Huang K-Y et al }{ }^{9} \\
\text { /2019/Taiwán }\end{array}$ & $\begin{array}{l}39 \text { gestantes } \\
\text { a término }\end{array}$ & $\begin{array}{l}\text { Terapia antirretroviral } \\
\text { combinada antes del } \\
\text { parto + } \\
\text { ZDV intravenosa } \\
\text { intraparto + } \\
\text { cesárea electiva + } \\
\text { carga viral < } \\
40 \text { copias } / \mathrm{ml}+ \\
\text { Prohibición de } \\
\text { lactancia materna }\end{array}$ & $\begin{array}{l}\text { Tasa de TMI } \\
\text { del } 0 \% .\end{array}$ & $\begin{array}{l}\text { La implementación } \\
\text { exitosa de la } \\
\text { intervención perinatal } \\
\text { contra el VIH disponible } \\
\text { redujo drásticamente } \\
\text { la tasa de transmisión } \\
\text { vertical del VIH. } \\
\text { La tasa de TMI fue } \\
\text { del } 0 \% \text { en Hospital } \\
\text { Universitario Nacional } \\
\text { de Taiwán después } \\
\text { del programa. }\end{array}$ \\
\hline $\begin{array}{l}\text { Posadas-Robledo } \\
\text { FJ }^{3} / 2018 \text { / México }\end{array}$ & $\begin{array}{c}1245 \\
\text { nacimientos }\end{array}$ & $\begin{array}{l}\text { Cesárea electiva }+ \\
\text { terapia antirretroviral } \\
(\text { TAR) }\end{array}$ & $\begin{array}{l}\text { Cesárea electiva } \\
\text { mostró un riesgo } \\
\text { relativo de } \\
0.7 \text { (IC del } 95 \% \\
0.06-0.09) .\end{array}$ & $\begin{array}{l}\text { La cesárea electiva } \\
\text { reduce el riesgo de } \\
\text { una prueba reactiva } \\
\text { para VIH en el } \\
\text { recién nacido. }\end{array}$ \\
\hline $\begin{array}{l}\text { Aho I et al }{ }^{12 /} \\
\text { 2018/Finlandia }\end{array}$ & $\begin{array}{c}212 \\
\text { mujeres. }\end{array}$ & $\begin{array}{l}\text { Carga viral } \\
<50 \text { copias } / \mathrm{ml} \\
\text { al momento del } \\
\text { parto vaginal } \\
\text { o cesárea. }\end{array}$ & $\begin{array}{l}80,0 \% \text { gestantes } \\
\text { mostró carga viral } \\
<50 \text { copias / ml en } \\
\text { la última medición } \\
\text { antes al parto. } \\
\text { En total, el } 74,5 \% \\
\text { de todas las } \\
\text { gestantes que } \\
\text { viven con el VIH } \\
\text { dieron a luz por } \\
\text { vía vaginal y la tasa } \\
\text { de cesáreas } \\
\text { electivas y cesáreas } \\
\text { de emergencia } \\
\text { fue del } 12,8 \% \\
\text { cada una }\end{array}$ & $\begin{array}{l}\text { La mayoría de las } \\
\text { mujeres que viven } \\
\text { con el VIH pueden } \\
\text { lograr un buen } \\
\text { control virológico } \\
\text { y dar a luz por } \\
\text { vía vaginal. } \\
\text { No se produjeron } \\
\text { transmisiones } \\
\text { perinatales } \\
\text { del VIH. }\end{array}$ \\
\hline $\begin{array}{l}\text { Scott R et al }\left.\right|^{11 /} \\
2017 / \\
\text { Latinoamérica } \\
\text { y El Caribe } \\
\text { (Argentina, } \\
\text { Bahamas, Brasil, } \\
\text { México, Perú y } \\
\text { Jamaica) }\end{array}$ & $\begin{array}{c}1,630 \\
\text { gestantes de } \\
40 \text { a más } \\
\text { semanas } \\
\text { de edad } \\
\text { gestacional } \\
\text { (EGA) }\end{array}$ & $\begin{array}{l}\text { Gestantes con } \\
\text { cargas virales } \\
<1000 \text { copias / } \\
\text { ml bien controlada }\end{array}$ & $\begin{array}{l}\text { Tasa de transmisión } \\
\text { vertical a las } \\
40 \text { semanas } \\
\text { o más de } \\
\text { EGA } 0,5 \% \\
\text { (IC del } 95 \% \\
0,2-1,4 \%) ; \\
\text { y menos de } \\
40 \text { semanas } \\
\text { EGA } 0,3 \% \\
(\text { IC del } 95 \% \\
0,1-0,7 \%)\end{array}$ & $\begin{array}{l}\text { En mujeres embarazadas } \\
\text { con VIH-1 bien controlado, } \\
\text { el riesgo de transmisión } \\
\text { de madre a hijo no difirió } \\
\text { significativamente } \\
\text { por EGA en el momento } \\
\text { del parto }\end{array}$ \\
\hline
\end{tabular}




\begin{tabular}{|c|c|c|c|c|}
\hline $\begin{array}{l}\text { Peters H } \\
\text { et/ } 2016^{13} / \\
\text { Reino Unido } \\
\text { e Irlanda }\end{array}$ & $\begin{array}{c}2.116 \\
\text { embarazos a } \\
\text { término con } \\
\text { terapia } \\
\text { antirretroviral } \\
\text { combinada } \\
\text { (TARc) y } \\
\text { RPM } \geq 4 \text { horas }\end{array}$ & $\begin{array}{l}\text { Gestantes A } \\
\text { Término con } \\
\text { TAR combinada y } \\
\text { carga viral } \\
<50 \text { copias/ml con } \\
\text { RPM } \geq 4 \text { horas } \\
\text { que culminaron } \\
\text { en parto vaginal } \\
\text { o cesárea } \\
\text { de emergencia }\end{array}$ & $\begin{array}{l}\text { Los resultados fueron } \\
\text { similares en los partos } \\
\text { a término en los que } \\
\text { la carga viral fue } \\
<50 \text { copias / ml: } \\
\text { la tasa de TMl fue } \\
\text { de } 0,14 \% \text { con } \\
\text { RPM } \geq 4 \text { horas } \\
\text { y } 0,12 \% \text { con RPM } \\
<4 \text { horas (OR } 1,14 \text {, } \\
\text { IC del } 95 \% \text { : } \\
0,07-18,27 \text { ) }\end{array}$ & $\begin{array}{l}\text { No se encontró } \\
\text { asociación entre la } \\
\text { duración del RPM } \\
\text { y la TMI en mujeres } \\
\text { con terapia } \\
\text { antirretroviral } \\
\text { combinada. }\end{array}$ \\
\hline $\begin{array}{l}\text { Townsend C et } \\
\text { al } 7 / 2014 \text { / } \\
\text { Reino Unido } \\
\text { e Irlanda. }\end{array}$ & $\begin{array}{c}12486 \\
\text { embarazos } \\
\text { únicos }\end{array}$ & $\begin{array}{c}\text { Carga viral (CV) } \\
<50 \text { copias / } \\
\text { ml y CV de } 50 \\
\text { a } 399 \text { copias } / \mathrm{ml}\end{array}$ & $\begin{array}{l}\text { CV <50 copias / } \\
\text { ml la TMl fue } 0,09 \% . \\
\text { CV de } 50 \text { a } \\
399 \text { copias } / \mathrm{ml} \\
\text { la TMl fue } 1.0 \%\end{array}$ & $\begin{array}{l}\text { Las tasas de TMH en } \\
\text { el Reino Unido e } \\
\text { Irlanda han seguido } \\
\text { disminuyendo } \\
\text { desde } 2006 \text {, } \\
\text { alcanzando } \\
\text { un mínimo histórico } \\
\text { de } 5 \text { por } 1000 \\
\text { en } 2010-2011 \text {. }\end{array}$ \\
\hline $\begin{array}{l}\text { Briand N et al }{ }^{10} \\
\text { / 2013/ Francia }\end{array}$ & $\begin{array}{l}\quad 4300 \\
\text { gestantes } \\
\text { a término }\end{array}$ & $\begin{array}{l}\text { Parto con baja } \\
\text { carga viral } \\
<50 \text { copias } / \mathrm{ml}\end{array}$ & $\begin{array}{l}\text { Carga viral } \\
<50 \text { copias } / \mathrm{ml} \text { : } \\
\text { parto vaginal y } \\
\text { cesárea electiva } 0.3 \% \text {. } \\
\text { Carga viral } \\
>10,000 \text { copias/ } \\
\text { ml: vaginal } 4.0 \% \text { y } \\
\text { cesárea electiva } 5.3 \%\end{array}$ & $\begin{array}{l}\text { Las mujeres infectadas } \\
\text { por el VIH que reciben } \\
\text { terapia antirretroviral } \\
\text { con baja carga viral } \\
\text { pueden optar con } \\
\text { seguridad por el parto } \\
\text { vaginal en ausencia } \\
\text { de factores de } \\
\text { riesgo obstétrico }\end{array}$ \\
\hline $\begin{array}{l}\text { Briand } N \text { et } \\
\text { al }^{14} / 2013 / \\
\text { Francia }\end{array}$ & $\begin{array}{l}11538 \\
\text { partos }\end{array}$ & $\begin{array}{l}\text { Utilización de } \\
\text { zidovudina } \\
\text { endovenoso } \\
\text { durante el parto }\end{array}$ & $\begin{array}{l}\text { Gestante con } \\
\text { carga viral } \\
\geq 1000 \text { copias } \\
\text { / ml, la tasa global } \\
\text { de Transmisión } \\
\text { vertical fue } \\
7.5 \% \text { sin ZDV } \\
\text { intravenosa frente } \\
\text { a 2,9\% con } \\
\text { ZDV intravenosa. }\end{array}$ & $\begin{array}{l}\text { La ZDV intravenosa } \\
\text { sigue siendo una } \\
\text { herramienta eficaz } \\
\text { para reducir la } \\
\text { transmisión en casos } \\
\text { de alta carga viral } \\
\geq 1000 \text { copias / ml, } \\
\text { incluso en mujeres } \\
\text { tratadas con terapia } \\
\text { antirretroviral } \\
\text { combinada TARc. } \\
\text { Sin embargo, para la } \\
\text { gran mayoría de las } \\
\text { mujeres con cargas } \\
\text { virales bajas al } \\
\text { momento del parto, } \\
\text { en ausencia de } \\
\text { factores de riesgo } \\
\text { obstétrico, la ZDV } \\
\text { intravenosa sistemática } \\
\text { parece ser innecesaria. }\end{array}$ \\
\hline $\begin{array}{l}\text { Velasquez } C^{8} \text { / } \\
2011 \text { / Perú }\end{array}$ & $\begin{array}{c}275 \\
\text { recién nacidos }\end{array}$ & $\begin{array}{c}\text { Gestante } \\
\text { recibe } \\
\text { antirretrovirales }\end{array}$ & $\begin{array}{c}6.9 \% \text { disminuyó } \\
\text { a } 0 \%\end{array}$ & $\begin{array}{l}\text { Los cambios realizados } \\
\text { en las guías nacionales } \\
\text { han producido } \\
\text { un impacto favorable } \\
\text { en la disminución de } \\
\text { nacimientos de niños } \\
\text { infectados por el VIH } \\
\text { en el Instituto Nacional } \\
\text { Materno Perinatal } \\
\text { en Perú }\end{array}$ \\
\hline
\end{tabular}


En relación a las estrategias de prevención de transmisión vertical del VIH durante la gestación, cabe señalar que, el seguimiento durante la atención prenatal tiene un impacto positivo en la prevención de la transmisión vertical del VIH, debido a que la atención prenatal es una oportunidad para brindar profilaxis materna y ofrecer antirretrovirales que reducen significativamente la transmisión vertical. Asimismo, es necesario cumplir con las recomendaciones dadas por $\mathrm{ACOG}^{6}$ que las gestantes infectadas con el VIH deben recibir asesoramiento sobre el beneficio potencial de uso de antirretrovirales y ofrecerles antes del parto una cesárea programada a las 38 semanas de gestación para reducir el riesgo de transmisión de madre a hijo.

En el Perú, la norma técnica del Ministerio de Salud sobre prevención de transmisión materno infantil del $\mathrm{VIH}^{4}$, recomienda realizar tamizaje de $\mathrm{VIH}$ en todas las gestantes y, a aquellas que resultan positivas, iniciar el tratamiento antirretroviral durante el embarazo y en el intraparto, culminar el embarazo vía cesárea electiva, suspender la lactancia materna y brindar profilaxis al recién nacido.

En relación a la cesárea electiva, es necesario tener en cuenta lo señalado por $\mathrm{ACOG}^{6}$ quienes recomiendan que las gestantes infectadas por el VIH cuyas cargas virales superen las 1000 copias/ml en el momento del parto o cerca del mismo, independientemente de la terapia antirretroviral antes del parto, o cuyos niveles se desconozcan, deben recibir asesoramiento sobre el beneficio potencial y ofrecerles una cesárea electiva a las 38 semanas de gestación para reducir el riesgo de transmisión de madre a hijo; y además estas gestantes deben recibir zidovudina intravenosa, idealmente 3 horas antes de la cesárea con una dosis de carga intravenosa en una hora $(2 \mathrm{mg} / \mathrm{kg})$, seguida de infusión continua durante 2 horas $(1 \mathrm{mg} / \mathrm{kg} / \mathrm{h}$ ) hasta el parto para lograr niveles adecuados del fármaco en la sangre materna y fetal. Al respecto, tal como reporta Briand $\mathrm{N}$ et $\mathrm{al}^{10}$ en relación a la estrategia de prevención de transmisión vertical del VIH, la cesárea electiva, es un método probado para prevenir la transmisión de madre a hijo, pero ya no se recomienda para mujeres con terapia antirretroviral que resulta en una baja carga viral (CV) $<400$ copias/ml descrito en Francia y $<1000$ copias / ml en las pautas de EE. UU; puesto que, las mujeres infectadas por el $\mathrm{VIH}$ que reciben terapia antirretroviral con baja carga viral pueden optar con seguridad por el parto vaginal en ausencia de factores de riesgo obstétrico.

Por otro lado, el Ministerio de Salud del Perú ${ }^{4}$ estipula el manejo con terapia antirretroviral (TAR) de la gestante con VIH según tres escenarios distintos, cuyo esquema de elección de terapia antirretroviral incluyen: Tenofovir 300mg (TDF) / Emtricitabina 200mg (FTC) + Raltegrabir 400mg (RAL) administrados por vía oral.
En caso hay contraindicación absoluta al uso de TDF: la primera opción es dar Zidovudina (AZT) / Lamivudina (3TC) + Raltegrabir (RAL) vía oral. El parto vaginal está indicado en la gestante con carga viral $<1000$ copias $/ \mathrm{ml}$ o cuando se presente dilatación cervical $>4$ centímetros o membranas amnióticas rotas; y la cesárea electiva, si la carga viral es $>1000$ copias $/ \mathrm{ml}$, para lo cual será programada a las 38 semanas de edad gestacional. Una vez que la gestante inicie trabajo de parto, independientemente del esquema antirretroviral que reciba, se le administrará zidovudina ( $A Z T)$ por vía endovenosa y continuar hasta el momento de ligar el cordón umbilical. El inicio del tratamiento antirretroviral debe realizarse a partir de 12 semanas de gestación.

Es importante destacar lo señalado por $\mathrm{ACOG}^{6}$ que las investigaciones establecidas y en curso han demostrado que el tratamiento de mujeres embarazadas infectadas por el VIH con terapia antirretroviral combinada puede lograr un riesgo de transmisión de madre a hijo de 1 a $2 \%$ o menos si se pueden mantener cargas virales maternas $<1000 \mathrm{copias} / \mathrm{ml}$, independientemente de la vía de administración o la duración de la rotura de membranas amnióticas antes del parto. El parto vaginal es apropiado para las mujeres embarazadas infectadas por el $\mathrm{VIH}$ que se han mantenido con terapia antirretroviral combinada y que tienen cargas virales de 1000 copias / ml o menos en el momento del parto o cerca del mismo. El riesgo de transmisión de madre a hijo en mujeres infectadas por el VIH con altas cargas virales puede reducirse realizando cesárea programada a las 38 semanas antes del inicio del trabajo de parto y antes de la rotura de membranas, junto con el uso de la terapia antirretroviral materna periparto.

Finalmente mencionar los reportes de Kiragu $\mathrm{K}$ et $\mathrm{al}^{15}$ y Lumaca $A$ et $a^{16}$ quienes señalan que las estrategias de prevención de la transmisión de madre a hijo son diversas: uso de terapia antirretroviral durante la gestación e intraparto, parto por cesárea programada o electiva, lactancia del recién nacido con fórmula y profilaxis neonatal.

Podemos concluir señalando que a pesar de los años transcurridos desde cuando se inició el uso de zidovudina en la gestante con VIH, la mayoría de los estudios seleccionados reportan que la reducción de la transmisión vertical del VIH se logra con el diagnóstico precoz del VIH durante el embarazo, uso de terapia antirretroviral durante la gestación y en el intraparto, cesárea electiva, baja carga viral, supresión de lactancia materna y profilaxis neonatal.

Declaración de conflictos de intereses: Los autores declaran no tener conflicto de intereses.

Financiamiento: Autofinanciado. 


\section{REFERENCIAS BIBLIOGRÁFICAS}

1. Nguyen RN, Ton QC, Tran QH, Nguyen TKL. Motherto-Child Transmission of HIV and Its Predictors Among HIV-Exposed Infants at an Outpatient Clinic for HIVIAIDS in Vietnam. HIVIAIDS - Research and Palliative Care. 2020; 12:253-261. doi:10.2147/hiv.s259592

2. Mandelbrot L, Tubiana R, Le Chenadec J, Dollfus C, Faye A, Pannier E, Matheron S, Khuong MA, Garrait V, Reliquet V, Devidas A, Berrebi A, Allisy C, Elleau C, Arvieux C, Rouzioux C, Warszawski J, Blanche S. No Perinatal HIV1 Transmission From Women With Effective Antiretroviral Therapy Starting Before Conception. Clinical Infectious Diseases, 2015: civ578. doi:10.1093/cid/civ578

3. Posadas-Robledo FJ. Embarazo y VIH ¿indicación absoluta de cesárea? Ginecol Obstet Mex.2018; 86(6):374-382. Doi: https://doi.org/10.24245/gom.v86i6.2018

4. Ministerio de Salud. Resolución Ministerial 1138-2019/ MINSA. Norma técnica de salud para la prevención de la transmisión materno infantil del VIH, sífilis y hepatitis. NT N¹59-MINSA-2019/DGIESP/. 2019.

5. Hospital Universitari Clínic Barcelona. Infección por VIH y gestación. Protocolos 2017.

6. American College of Obstetricians and Gynecologists. Labor and delivery management of women with human immunodeficiency virus infection. ACOG Committee Opinion No. 751. Obstet Gynecol 2018; 2018:131-7.

7. Townsend CL, Byrne L, Cortina-Borja M, et al. Earlier initiation of ART and further decline in mother-to-child HIV transmisión rates, 2000-2011. AIDS. 2014;28: 1049-57. https:// journals.Iww.com/aidsonline/pages/articleviewer.aspx?year=2014\&issue $=04240 \&$ article=00014\&type=Abstract

8. Velásquez C. Resultados de la aplicación de tres guías nacionales para prevenir la transmisión vertical del VIH en el Instituto Nacional Materno Perinatal. Lima, Perú. Rev Peru Med Exp Salud Publica. 2011;28(3):492-6.

9. Huang K-H, Li Y-P, Shih Ch-Ch, Lin CH, Kang J, Lin MW, Hsu WW, Tai Y-Y, Lin S-H, Ho H-N. Mother-to-child transmission of HIV: An 11-year experience in a single center and HIV prevention effectiveness in Taiwan. Journal of the Formosan Medical Association. 2019; 118: 1211e1217.

10. Briand N, Jasseron C, Sibiude J, et al. Cesarean section for HIV-infected women in the combination antiretroviral therapies era, 2000-2010. Am J Obstet Gynecol 2013; 209: 335. e1-12. https://www.ncbi.nlm.nih.gov/pubmed/23791563

11. Scott R, Chakhtoura N, Burke M, Cohen R, Kreitchmann R. Delivery After 40 Weeks of Gestation in Pregnant Women With Well-Controlled Human Immunodeficiency Virus. Obstet Gynecol. 2017;130(3):502-510. doi: 10.1097/ AOG.0000000000002186.

12. Aho I, Kaijomaa M, Kivelä P, Surcel H-M, Sutinen J, Heikinheimo $\mathrm{O}$, et al. Most women living with HIV can delive vaginally-National data from Finland 1993-2013. PLoS ONE.2018;13(3): e0194370. https://doi.org/10.1371/journal.pone.0194370

13. Peters H, Byrne L, De Ruiter A, Francis K, Harding K, Taylor $\mathrm{GP}$, et al. Duration of ruptured membranes and mother-tochild HIV transmission: a prospective population-based surveillance study. BJOG 2016; 123:975-81.

14. Briand N, Warszawski J, Mandelbrot L, Dollfus C, Pannier E, Cravello $L$, et al. Is intrapartum intravenous zidovudine for prevention of mother-to-child HIV-1 transmission still useful in the combination antiretroviral therapy era? ANRS-EPF C01-C011 Study Group. Clin Infect Dis.2013;57:903-14
15. Kiragu K, Collins L, Von Zinkernagel D, Mushavi A. Integrating PMTCT into maternal, newborn, and child health and related services. J Acquir Immune DeficSyndr. 2017;75: S36-S42

16. Lumaca A, Galli L, de Martino M, Chiappini E. Paediatric HIV-1 infection: updated strategies of prevention motherto-child transmisión. Journal of Chemotherapy. 2018. DOI: 10.1080/1120009X.2018.1451030

\section{Correspondencia:}

Katherin Faviola Moreno Reyes

Dirección: San Diego Mz C Lote 18 Valle Azul II etapaSan Martín de Porres. Lima-31.

Correo: katherin_r28@hotmail.com

Teléfono: 962198849 